\title{
Public vs. private health care: What does it mean for medical students?
}

$\mathrm{O}$ n June $9^{\text {th }}, 2005$ the Supreme Court of Canada ruling on the Chaoulli vs. Quebec case challenged the notion that private insurance should not be allowed for medically necessary health care services. Coupled with growing wait lists, lack of health human resources and rapidly rising expenditures, this landmark decision has renewed discussion about the role of public and private health care in Canada.

Currently, few health jurisdictions have provided a clear role for private health care in Canada. Alberta has proposed the "Third Way" where patients would be able to use private insurance to purchase surgical services and physicians would be permitted to work in both the public and private systems. The Quebec government has introduced policies that will allow private clinics to operate under the umbrella of the public health care system. Yet, it is unclear whether these movements will address the chronic pitfalls of the health care system or will cause further fragmentation. Further, evidence comparing the public and private system is inconclusive to date. This is primarily due to the difficulty in making comparisons between two systems that provide different services. Evaluation of US data has shown that public hospitals provide a wide variety of primary, secondary and tertiary services. Such complexity and variation in afforded treatment complicates outcome measurements. In contrast, private hospital services tend to focus more on high technology procedures such as hip and cataract surgeries that allow for easier outcome measurement and economic efficiencies.

As medical students, potential policy changes for health care delivery will undeniably impact our future training and, ultimately, our medical careers. However, it is unclear if these reforms will positively or negatively impact medical education. If these changes improve the overall capacity of the system to provide services, this might mean more clinical and teaching opportunities for trainees. However, if these additional services are offered only through a private operator then access to such opportunities may be limited. In addition, the development of a parallel private system may potentially impact the availability of physicianteachers. If students are given the choice of working privately, it may limit their access to teaching and research opportunities. Few researchers have addressed the aforementioned issues.

So, what does the above mean for medical students? At this point, we can only speculate. Once the exact roles, responsibilities and interaction of private and public medical systems are defined, only then can medical education find its fit. Medical students will inherit the proposed changes to the health care system and thus have a vested interest in this debate. It is important that our voices are heard by both physicians, policy makers, and other stakeholders to ensure that medical students have a strong health care system that provides optimal teaching and training opportunities. Any change must focus on creating effective and timely health care policies for all patients regardless of ability to pay. Reform must be based on sound evidence and not politics surrounding the public-private debate.

\section{Ryan Sommers \\ Dalhousie Medical School, Class of 2006}


medical doctors

\section{volunteer today with MSF}

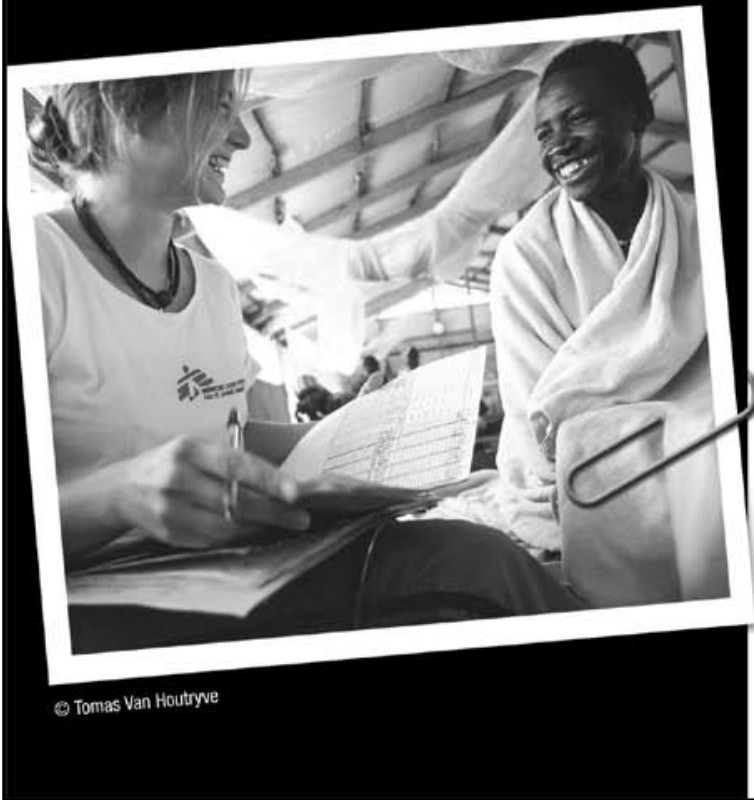

Who we are

Médecins Sans Frontières/Doctors Without Borders (MSF) is the world's leading emergency medical humanitarian aid organization.

We offer assistance to populations in distress, to victims of disaster and of armed conflict, without discrimination and irrespective of race, religion, creed or political affiliation.

Volunteers work where the need is immediate, combining direct medical care with a commitment to bearing witness and speaking out about the underlying causes of suffering.

Who we need

MDs particularly well-suited for work with MSF

are those with training in:

- general practice

- family medicine

- emergency medicine

- internal medicine

- surgery

- anesthesiology

- obstetrics and gynecology

- paediatrics

- community medicine

- infectious disease (particularly HIV/AIDS and TB)

\section{Criteria}

- full and current registration/license

- minimum 1 to 2 years post-registration experience

- available to work for a minimum of 6 months

- relevant travel and/or work experience in a developing country or in remote parts of Canada

for more information: www.msf.ca 1.800 .982 .7903
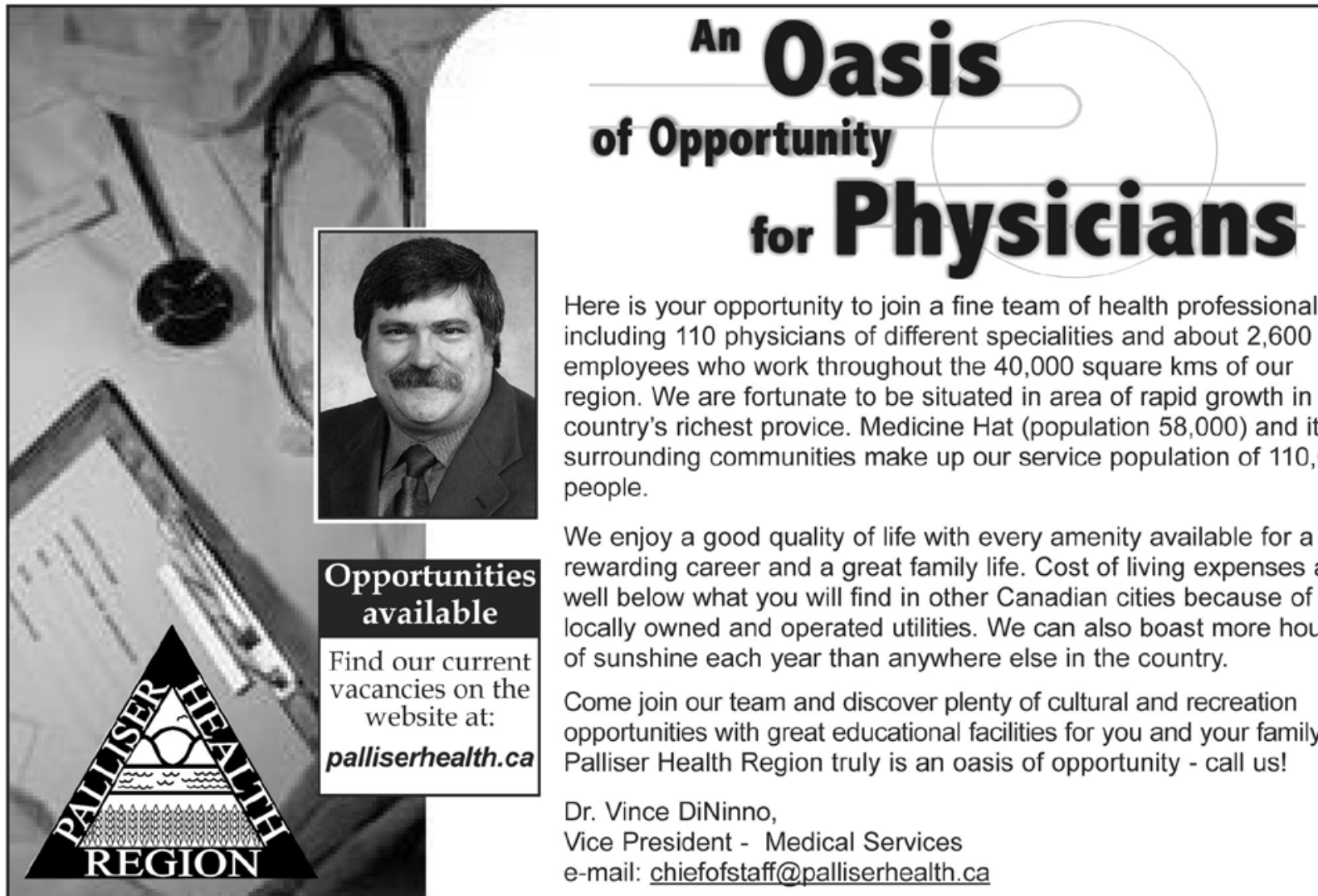

Here is your opportunity to join a fine team of health professionals, including 110 physicians of different specialities and about 2,600 employees who work throughout the 40,000 square $\mathrm{kms}$ of our region. We are fortunate to be situated in area of rapid growth in the country's richest provice. Medicine Hat (population 58,000) and its 47 surrounding communities make up our service population of 110,000 people.

We enjoy a good quality of life with every amenity available for a rewarding career and a great family life. Cost of living expenses are well below what you will find in other Canadian cities because of locally owned and operated utilities. We can also boast more hours of sunshine each year than anywhere else in the country.

Come join our team and discover plenty of cultural and recreation opportunities with great educational facilities for you and your family. Palliser Health Region truly is an oasis of opportunity - call us!

Dr. Vince DiNinno,

Vice President - Medical Services

e-mail: chiefofstaff@palliserhealth.ca 